\title{
The Importance of Pragmatic over Explanatory Randomised Controlled Trial in Musculoskeletal Physiotherapy Practice
}

\author{
Collins Ogbeivor ${ }^{1 *}$ and Farai Chitambo ${ }^{2}$ \\ ${ }^{1}$ Consultant Physical Therapist, Rehabilitation Department, John Hopkins Healthcare Aramco, Saudi Arabia \\ ${ }^{2}$ Senior Physical Therapist, Rehabilitation Department, John Hopkins Healthcare Aramco, Saudi Arabia
}

*Corresponding author: Dr Collins Ogbeivor, Consultant Physical Therapist, Rehabilitation Department, John Hopkins Healthcare Aramco, Dhahran, P O Box 34465, Kingdom of Saudi Arabia

\begin{abstract}
Depending on the choice of research methodology, there are several research designs such as a single observational case study, a cohort or case-controlled design, nonrandomised and randomised controlled trials (RCTs). While RCTs are widely considered as the gold standard for assessing the effectiveness of different physiotherapy interventions, there are two types of RCT mainly explanatory and pragmatic RCT. It is the opinion of the author that a pragmatic RCT approach that not only have realistic treatment sessions but also involve less costs and personnel are best suited for musculoskeletal studies undertaken in a normal clinical environment to enhance their generalisation.
\end{abstract}

\section{Introduction}

Research evidence suggests the number of physiotherapy treatment sessions varies over treatment episodes [1], however, according to the Chartered Society of Physiotherapy [2] the average physiotherapy (face-to-face) treatment sessions per episode of care for a patient was on average four-with a first to follow-up ratio of 1:3.4. The minimum number of physiotherapy treatments per episode was one with maximum of six treatment sessions. These figures were from the research findings of a large comprehensive review of physiotherapy outpatient services across the United Kingdom by JJ Consulting on behalf of the Chartered Society of Physiotherapy [2]. These figures are important benchmarks for Physiotherapy managers and physiotherapy service providers to guide them on staffing levels and management of caseloads to support a range of areas such as business planning, capacity and demand management, and service re-design. Thus, it is important for researchers and those funding physiotherapy researches to take into consideration the average number of treatment sessions that occurs in normal clinical practice when developing research designs that investigates the effectiveness of treatment interventions in musculoskeletal practice. This is so that the findings of such research could easily be transferable to real physiotherapy clinical situations. Pragmatic randomized controlled trials (RCTs) are designed and conducted to establish the clinical effectiveness of interventions i.e. does this intervention work under usual clinical conditions?. According to Loudon et al., [3] for a trial to fulfil the requirements of the design and conduct of a pragmatic RCT, it should have the nine dimensions for assessing the level of pragmatism in a trial. These include eligibility, recruitment, setting, and organisation, flexibility in delivery, flexibility in adherence, follow-up, primary outcome and primary analysis. Follow-up visits (timing and frequency) are pre-specified in the protocol of RCTs. However, "follow-up visits are more frequent than typically would occur outside the trial (i.e., under usual care)" [3] (See Table 1 below). 
Table 1: A PRECIS follow-up assessment of some trials.

\begin{tabular}{|c|c|c|}
\hline \multicolumn{3}{|c|}{ Follow-up: Intervention/comparison } \\
\hline Study & Intervention/comparison & Comments \\
\hline Alp 2014 [5] & $\begin{array}{l}\text { Self-management supervised exercises versus group } \\
\text { biomechanical exercise - Core stabilization ( } 45-60 \text { minutes } 3 \\
\text { times per week) }\end{array}$ & Study length: 6 weeks treatment \\
\hline Bronfort et al 2011 [4] & Strengthening versus spinal manipulation & Study length: 6 weeks treatment \\
\hline Gladwell 2006 [23] & $\begin{array}{c}\text { Pilates (class once a week and } 2 \text { sessions per week at home) } \\
\text { versus Usual care }\end{array}$ & Study length: 6 weeks treatment \\
\hline Harts 2008 [24] & Core stability (frequency unclear) versus Waiting list & Study length: 8 weeks treatment \\
\hline Lawand 2015 [25] & Individual biomechanical exercise - Stretching & Study length: 24 weeks ( 12 weeks of treatment) \\
\hline Lee 2015 [26] & $\begin{array}{c}\text { Individual Biomechanical exercise - McKenzie ( } 5 \text { times a week) } \\
\text { versus electrotherapy - interferential therapy }\end{array}$ & Study length: 2 weeks \\
\hline Machado 2010 [27] & Mckenzie (frequency unclear versus usual care) & Study length: 3 weeks treatment \\
\hline Masharawi 2013 [29] & Core stabilisation (2x per week) versus Usual care & Study length: 4 weeks treatment \\
\hline Rasmussen-barr 2009 [30] & $\begin{array}{l}\text { Core stability ( } 45 \text { minutes sessions weekly and at home } 15 \\
\text { minutes daily) versus usual care }\end{array}$ & Study length: 8 weeks treatment \\
\hline Vincent 2014 [31] & $\begin{array}{l}\text { Individual Biomechanical exercise - Stretching ( } 3 \text { times a week for } \\
\text { one-on-one training sessions) versus usual care }\end{array}$ & Study length: 4 months \\
\hline
\end{tabular}

Table 1 shows that in some RCTs on musculoskeletal physiotherapy interventions that there are difficulties with transferring the results of those trials into daily clinical practice due to their unrealistic treatment occasions. For example, an RCT [4] that was conducted to evaluate the relative efficacy of strengthening exercises versus spinal manipulation on LBP patients were provided a one-hour session twice per week for 6 weeks - bringing the total treatment episodes to 12 one-hour treatment sessions. Similarly, [5] in a RCT of management LBP that investigated self-management (unsupervised exercise) versus group biomechanical exercise used 45-60 minute, 3 times per week for 6 weeks as their treatment regime. The findings of these trials are in sharp contrast to the [2] findings on the maximum number of treatments per episode care, which was six. Furthermore, anecdotal evidence suggests that initial musculoskeletal physiotherapy treatment is maximum of one hour and follow-up treatment ranges from 20-45 minutes. The implications of the treatment regimens of both RCTs [4,5] suggests that they have unrealistic treatment occasions which cannot be transferred to practice. It is therefore imperative for clinical trials investigating the effects of physiotherapy interventions to take into consideration that study designs should mirror what occur in normal clinical practice. There are many different research designs ranging from a single observational case study, a cohort or casecontrolled design, to experimental studies such as nonrandomised and randomised controlled trials (RCTs). Each design has its own strengths and weaknesses. The choice of methodology may be influenced by factors such as the research question, ethical issues, sample size and funding [6]. Although case studies are likely to demonstrate clinically significant improvement in outcomes of pain and function, it must not be forgotten that they cannot rule out the effects of natural resolution, bias and other confounders such as the real cause of the improvement [7]. However, single case studies should provide some motivation for conducting the appropriate and necessary trials such as nonRCTs and RCTs [8]. NonRCTs can detect associations between an intervention and an outcome, however they cannot rule out the possibility that the association was caused by a third factor linked to both intervention and outcome [9]. RCTs are widely considered as the gold standard for assessing the effectiveness of different interventions such as shoulder injections, because they allow us to be confident that a difference in outcome can be directly attributed to a difference in the treatments, rather than some other confounding variables (age and gender) $[10,11]$. However, other factors, such as patient's clinical experience of the intervention, as well as the quality and quantity of treatment received have been suggested to play a role in determining treatment outcomes [12]. Therefore, an RCT that combines these aspects by investigating the effectiveness of the interventions in real life clinical situation is important. To achieve this, RCTs investigating the effectiveness of two interventions (usual or routine versus intervention) should as part of their research methodology take into consideration the practicality of number treatment sessions, follow-up regimes and outcomes that are comparable to those observed in every day clinical practice both in community and acute settings. This so that any treatment effect from those studies can be easily transferable to normal clinical practice situations. RCTs help to reduce the risks of bias (threats to interval validity), mostly selection bias, and are thus best suited for research designs about the effectiveness of different interventions [13]. However, it is the opinion of Cochrane, that randomisation does not, of itself, enhance the applicability of the results of a trial (external validity) to situations other than the exact one in which it was conducted [14]. It is possible for a trial to be 
free of bias but lacking in its application beyond the immediate clinical environment in which it was conducted [12]. This view was strongly re-echoed Rothwell [15] which it stated: "Lack of consideration of external validity is the most frequent criticism by clinicians of RCTs, systematic reviews, and clinical guidelines" [15]. To resolve this Treweek \& Zwarenstein [13] has suggested the use of well-designed trials that adopt a pragmatic approach. Therefore, it is my opinion that for a pragmatic RCT approach to be adopted as a research design, it should have realistic treatment occasions and transferable to normal clinical environment where most people with musculoskeletal conditions are easily diagnosed and treated [16] to enhance its generalisation.

\section{Pragmatic Versus Explanatory Randomised Controlled Trial}

Schwartz \& Lellouch [17] describe two different types of RCT, explanatory and pragmatic. They proposed a distinction between explanatory and pragmatic trials. It is their view that many trials (such as explanatory trials) were limited in their applicability beyond the artificial, laboratory environment. Explanatory trials are aimed at validating a physiological hypothesis by specifically proving a causal relationship between administration of a treatment (a drug) and a physiological outcome (such as inflammation) [17]. Although pragmatic trials do not necessarily decrease occasions of service or necessarily curtail follow-up, they provide an explanation between interventions and treatment outcomes, and they are intended to inform healthcare decision-making. This decision involves the choice between two or more treatments occurring in real life clinical environment. On the other hand, explanatory trials provide knowledge about the effects of precisely defined interventions applied to selected groups under highly controlled conditions; however, they are not applicable in normal physiotherapy practice that lack such highly controlled environments. Pragmatic trials have been offered as a solution in that they retain the rigour of randomisation but are still applicable to normal clinical practice [18]. It is for these reasons that musculoskeletal studies should adopt a pragmatic approach which takes into account realistic treatment occasions which occurs in a normal clinical so that findings from such trials can be easily transferable to practice. For example Eadie et al [19], in a pragmatic RCT investigated exercise versus group biomechanical exercise in chronic low back patients using a one-hour session per week, which is what obtains in every day practice. The implication of this study's findings is that it has realistic treatment occasion that is easily transferable to practice. The differences between the two approaches are also highlighted in the use of efficacy and effectiveness [20]. Explanatory trials deal with efficacy as these studies assess differences in effect between two or more conditions under ideal, highly controlled conditions. Although the tight controls of explanatory trials result in maximal internal validity, external validity could be lost [33]' because replicating them under normal clinical practice is difficult. Explanatory trials are thought to be well suited to medical drug trials, which are usually double or triple blinded, and involve the use of a placebo control group [33]. Pragmatic RCTs utilise effectiveness, which assesses differences in effect between two or more conditions in normal clinical circumstances, thus retaining internal validity and enhancing external validity [33]. It is the opinion of It is the opinion of Alford [33], that pragmatic RCTs are generally more suited to assessing musculoskeletal interventions such as exercise prescription for managing low back or shoulder pain. Explanatory trials are usually more expensive, take more time and involve more personnel, unlike pragmatic trials. These difficulties are the reasons why a pragmatic approach is best suited for musculoskeletal research within the community. The benefits are that less extra costs or personnel that would be involved in such studies because they are more likely to take place within normal clinical hours with the usual staff involved.

\section{Pragmatic Randomised Controlled Trial-Why it is Important}

In a normal community practice where most people with musculoskeletal pain are diagnosed and managed [16], a pragmatic RCT design is important if they have realistic treatment, occasions, which can be transferred to practice. A pragmatic RCT is aimed at determining the effectiveness of two or more interventions under the usual conditions or real-life settings in which they are applied [21]. Pragmatic trials including RCT are aimed at ensuring that the care delivered in the setting in which trials are conducted matches the care delivered in the setting to which its results are applied [3]. Pragmatic RCTs are generally linked with clinical practice and they incorporate clinical outcomes that are relevant to inform decision makers such as patients, clinicians, health commissioners and policy makers about interventions that are applicable to a wide range of clinical settings [21]. These trials adopt minimal exclusion criteria in order for the patients to reflect those receiving care within the normal population [21]. This is so that treatment interventions and decision making by both the patients and healthcare providers regarding the management of musculoskeletal conditions could be enhanced. Musculoskeletal studies should include participants drawn from a population of patients attending a community (MSK) service as they would be representative of the general population. The benefits of pragmatic trials include less costs and personnel because they are more likely to take place within normal clinical hours with the usual staff involved. The nine dimensions for assessing the level of pragmatism in a trial (Figure 1 ), as proposed in the pragmatic-explanatory continuum indicator summary 2 (PRECIS-2) tool should be adopted by musculoskeletal studies so that they can be easily transferred to practice [3]. With 
the current economic climate and given the pressure to improve healthcare delivery within the community, pragmatic RCTs have received widespread support and acceptance from clinicians, researchers and policy makers [22]. Healthcare commissioners and policy makers are very interested in pragmatic trials because they are designed to answer important and relevant questions, which are centred on comparative effectiveness of interventions in the normal clinical practice [23]. However, those trials should not only have realistic treatment sessions but also involve less costs and personnel. Since the local Clinical Commissioning who commissions musculoskeletal practice are interested in knowing the clinical outcomes, involving them and GPs during the planning stages of musculoskeletal research is very important. This is consistent with the suggestion by [22] that decision makers such as healthcare providers and policy makers should be included in the design of pragmatic trials.

Figure 1: The nine dimensions for assessing the level of pragmatism in a trial, as proposed in the pragmatic-explanatory continuum indicator summary 2 (PRECIS-2) tool (Adopted from Loudon et al, 2015) used in a pragmatic RCT in a community MSK trial on shoulder pain (Ogbeivor et al, 2019).

\begin{tabular}{|c|c|c|}
\hline Dimension & Assessment of Pragmatism - PRECIS-2 Tool & What this study did using the PRECIS-2 Tool \\
\hline Eligibility & $\begin{array}{l}\text { To what extent are the participants in the } \\
\text { trial similar to those who would receive this } \\
\text { intervention if it was part of usual care? }\end{array}$ & $\begin{array}{l}\text { The study participants were patients that have been referred to the service } \\
\text { by their general practitioner with shoulder pain who usually could be treated } \\
\text { with standard care or intervention using treatment approach. }\end{array}$ \\
\hline Recruitment & $\begin{array}{l}\text { How much extra effort is made to recruit } \\
\text { participants over and above what would be used } \\
\text { in the usual care setting to engage with patients? }\end{array}$ & $\begin{array}{l}\text { The service where thus study took place receives referrals from } 33 \text { GP } \\
\text { practices in the area. Therefore, prior to the study, presentations were made } \\
\text { to the general practitioner's in the area via the clinical commissioning group } \\
\text { (CCG) and to the Extended Scope Practitioners and the Physiotherapists } \\
\text { at the researcher's place of work to inform them of the study and enhance } \\
\text { recruitment of participants. }\end{array}$ \\
\hline Setting & $\begin{array}{l}\text { How different are the settings of the trial from } \\
\text { the usual care setting? }\end{array}$ & $\begin{array}{l}\text { All the participants recruited to the study were from a population of patients } \\
\text { attending a community Musculoskeletal service. }\end{array}$ \\
\hline Organisation & $\begin{array}{l}\text { How different are the resources, provider } \\
\text { expertise, and the organisation of care delivery } \\
\text { in the intervention arm of the trial from those } \\
\text { available in usual care? }\end{array}$ & $\begin{array}{l}\text { No extra cost or personnel was involved in this study. The clinicians involved } \\
\text { in this study and the treatment they provided were similar to the care they } \\
\text { would normally provide in their clinical practice. }\end{array}$ \\
\hline $\begin{array}{l}\text { Flexibility in } \\
\text { delivery }\end{array}$ & $\begin{array}{l}\text { How different is the flexibility in how the } \\
\text { intervention is delivered and the flexibility } \\
\text { anticipated in usual care? }\end{array}$ & $\begin{array}{c}\text { The flexibility applied to the intervention in this study was similar to the } \\
\text { usual care. }\end{array}$ \\
\hline $\begin{array}{l}\text { Flexibility in } \\
\text { adherence }\end{array}$ & $\begin{array}{l}\text { How different is the flexibility in how } \\
\text { participants are monitored and encouraged to } \\
\text { adhere to the intervention from the flexibility } \\
\text { anticipated in usual care? }\end{array}$ & $\begin{array}{l}\text { In this study standard after care and post-injection information were } \\
\text { provided verbally and in the form of information leaflet based usual care. }\end{array}$ \\
\hline Follow-up & $\begin{array}{l}\text { How different is the intensity of measurement } \\
\text { and follow-up of participants in the trial from } \\
\text { the typical follow-up in usual care? }\end{array}$ & $\begin{array}{l}\text { Participants in the study were assessed three times during the study period, } \\
\text { at } 0 \text { (baseline), } 8 \text { and } 12 \text { weeks. The } 0 \text { and } 8 \text { weeks' timeframe is common in } \\
\text { normal clinical practice and previous authors (Akgun et al 2004) have used } \\
\text { the } 12 \text { weeks' follow-up period. At follow-up, the outcomes of the injection } \\
\text { were evaluated via a telephone call similar to normal clinical practice. }\end{array}$ \\
\hline Primary outcome & $\begin{array}{l}\text { To what extent is the trial's primary outcome } \\
\text { directly relevant to participants? }\end{array}$ & $\begin{array}{l}\text { The primary outcome - shoulder pain disability index and numeric pain } \\
\text { rating scale that were used used in normal clinical practice. }\end{array}$ \\
\hline Primary analysis & $\begin{array}{l}\text { To what extent are all data included in the } \\
\text { analysis of the primary outcome? }\end{array}$ & $\begin{array}{l}\text { In this study, all data were included in the analysis of the primary outcome. } \\
\text { Once a participant is randomised to an arm of treatment, they should be } \\
\text { analysed in the group to which they were allocated to after randomisation. }\end{array}$ \\
\hline
\end{tabular}

\section{Conclusion}

While RCTs are widely considered as the gold standard for assessing the effectiveness of different interventions such as shoulder injections, there are basically two types of RCT mainly explanatory and pragmatic RCT. Although each design has its own strengths and weaknesses, the choice of methodology may be influenced by factors such as the research questions, ethical issues and clinical practice environment [6]. It is the opinion of the author that a pragmatic RCT approach that not only have realistic treatment sessions but also involve less costs and personnel are best suited for musculoskeletal studies undertaken in a normal clinical environment to enhance their generalisation.

\section{References}

1. Swinkels IC, Wimmers RH, Groenewegen PP, van den Bosch WJ, Dekker J, et al. (2005) What factors explain the number of physical therapy treatment sessions in patients referred with low back pain; a multilevel analysis. BMC health services research p. 5: 74.

2. Chartered Society of Physiotherapy A survey of NHS Physiotherapy waiting times, workforce and caseloads in the UK 2010-2011. Report by JJ Consulting, Northern Ireland, Scotland.

3. Loudon K, Treweek S, Sullivan F, Donnan P, Thorpe K E, et al. (2015) The PRECIS-2 tool: designing trials that are fit for purpose. British Medical Journal p. 350: 2147. 
4. Bronfort G, Maiers MJ, Evans RL, Schulz CA, Bracha Y, et al. (2011) Supervised exercise, spinal manipulation, and home exercise for chronic low back pain: a randomized clinical trial. The spine journal: official journal of the North American Spine Society 11(7): 585-598.

5. Alp A, Mengi G, Avsaroglu AH, Mert M, Sigirli D (2014) Efficacy of corestabilization exercise and its comparison with home-based conventional exercise in low back pain patients. Turkiye Fiziksel Tip Ve Rehabilitasyon Dergisi 60(1): S36-S42.

6. Hicks C (1999) Research Methods of Clinical Therapist: Applied Project Design and Analysis (4th edition) London: Churchill Livingstone.

7. Ainsworth R \& Lewis JS (2007) 'Exercise therapy for the conservative management of full thickness tears of the rotator cuff: a systematic review' British Journal of Sports Medicine 41 (4): 200 - 210.

8. Egger MD, Smith G \& Altman DG (2007) Systematic Reviews in Health Care: Meta-analysis in context. London: BMJ Publishing Group pp.

9. Sibbald B, Roland M (1998) Understanding controlled trials: Why are randomized controlled trials important? British Medical Journal 316(7126): 201.

10. McGovern DPB (2001) Randomized controlled trials. In: McGovern DPB, Valori RM, Summerskill WSM, eds. Key topics in evidence-based medicine. Oxford: BIOS Scientific Publishers: 26-9.

11. Aveyard H (2007) Doing a Literature Review in Health and Social Care. A Practical Guide Maidenhead, New York: Open University Press pp.

12. Black N (1996) Why we need observational studies to evaluate the effectiveness of health care. British Medical Journal 312(7040): 12151218

13. Treweek S, Zwarenstein M (2009) Making trials matter: pragmatic and explanatory trials and the problem of applicability Trials 10(37): 1-9.

14. Cochrane AL (1972) Effectiveness and efficiency: Random reflections on health services' London, UK: Nuffield Provincial Hospitals Trust Journal of the Royal Society for the Promotion of Health 92(5): 270-270.

15. Rothwell PM (2005) External validity of randomised controlled trials: To whom do the results of this trial apply? Lancet 365(9453): 82-93.

16. Hanchard NCA, Lenza M, Handoll HHG, Takwoingi Y (2013) Physical tests for shoulder impingements and local lesions of bursa, tendon or labrum that may accompany impingement' Cochrane Data base of Systematic Reviews p. 4: CD007427.

17. Schwartz D, Lellouch J (1967) Explanatory and pragmatic attitudes in therapeutical trials Journal of Chronic Diseases 20(8): 637-648.

18. Relton C, Torgerson D, O'Cathain A, Nicholl J (2010) Rethinking pragmatic randomised controlled trials: Introducing the "cohort multiple randomised controlled trial" design British Medical Journal 340(1): 1066.

19. Eadie J, van de Water AT, Lonsdale C, Tully MA, van MW, et al. (2013) Physiotherapy for sleep disturbance in people with chronic low back pain: results of a feasibility randomized controlled trial. Archives of Physical Medicine and Rehabilitation 94(11): 2083-2092.

20. Sheikh A, Smeeth L, Ashcroft R (2002) Randomised controlled trials in primary care: scope and application. British Journal of General Practice 52(482): 746-751.

21. Califf RM, Sugarman J (2015) Exploring the ethical and regulatory issues in pragmatic clinical trials. Clinical Trials 12(5): 436-441.
22. Whicher DM, Miller JE, Dunham KM, Joffe S (2015) Gatekeepers for pragmatic clinical trials. Clinical Trials 12(5): 442-448.

23. Patsopoulos NA (2011) A pragmatic view on pragmatic trials. Clinical Research 13(2): 1-8.

24. Gladwell V, Head S, Hagger M, Beneke R (2005) Does a Program of Pilates Improve Chronic Non-Specific Low Back Pain? Journal of sport rehabilitation 15(4): 338-350.

25. Harts C, Helmhout P, de Bie R (2008) A high-intensity lumbar extensor strengthening program is little better than a low-intensity program or a waiting list control group for chronic low back pain: a randomised clinical trial. The Australian journal of physiotherapy 54: 23-31.

26. Lawand P, Lombardi Júnior, I, Jones, A, Jones A, Sardim C, et al. (2015) Effect of a muscle stretching program using the global postural reeducation method for patients with chronic low back pain: a randomized controlled trial. Joint Bone Spine 82(4): 272-277.

27. Lee M, Song C, Jo Y, Ha D, Han D (2015) The effects of core muscle release technique on lumbar spine deformation and low back pain. Journal of physical therapy science 27(5): 1519-1522.

28. Machado LA, Maher CG, Herbert RD, Clare H, McAuley J (2005) The McKenzie Method for the management of acute non-specific low back pain: design of a randomised controlled trial [ACTRN012605000032651]. BMC Musculoskeletal Disorder pp. 6: 50.

29. McKee M, Britton A, Black N, McPherson K, Sanderson C, et al. (1999) Interpreting the evidence: choosing between randomised and nonrandomised studies. British Medical Journal 319(7205): 312-315.

30. Masharawi, Youssef and Nadaf, Nedal (2013) The Effect of Non-weight Bearing Group-exercising on Females with Non-specific Chronic Low Back Pain: A Randomized Single Blind Controlled Pilot Study. 26(4): 353-359.

31. Rasmussen Barr E, Ang B, Arvidsson I, Nilsson-Wikmar L (2009) Graded exercise for recurrent low-back pain: a randomized, controlled trial with 6-, 12-, and 36-month follow-ups. Spine (Phila Pa 1976). 34(3): 221-228.

32. Vincent HK, Vincent KR, Seay AN (2014) Back strength predicts walking improvement in obese, older adults with chronic low back pain. PMR 6(5): 418-426.

33. Alford L (2007) 'On differences between explanatory and pragmatic clinical trials' New Zealand Journal of Physiotherapy 35(1): 12 - 16.

34. Masharawi, Y and Nadaf, N (2013) The Effect of Non-weight Bearing Group-exercising on Females with Non-specific Chronic Low Back Pain: A Randomized Single Blind Controlled Pilot Study. 353 - 359.

35. Ogbeivor, C, Bandaru, S, Milton, C (2019) A comparison of the effectiveness of lateral versus posterior approach to shoulder injection in patients with subacromial impingement syndrome: A pragmatic randomized controlled trial. Musculoskeletal Care. 257- 268. https:// doi.org/10.1002/msc.1416

36. Tunis SR, Stryer DB, Clancy CM (2003) Practical Clinical Trials: Increasing the Value of Clinical Research for Decision Making in Clinical and Health Policy. JAMA. 290(12):1624-1632. doi:10.1001/jama.290.12.1624.

37. Tunis, SR (2005) A Clinical Research Strategy to Support Shared Decision Making. Health Affairs 2005 24:1, 180-184 
CC (i) This work is licensed under Creative Commons Attribution 4.0 License

To Submit Your Article Click Here:

Submit Article

DOI: $10.32474 / O S M O A J .2020 .04 .000191$

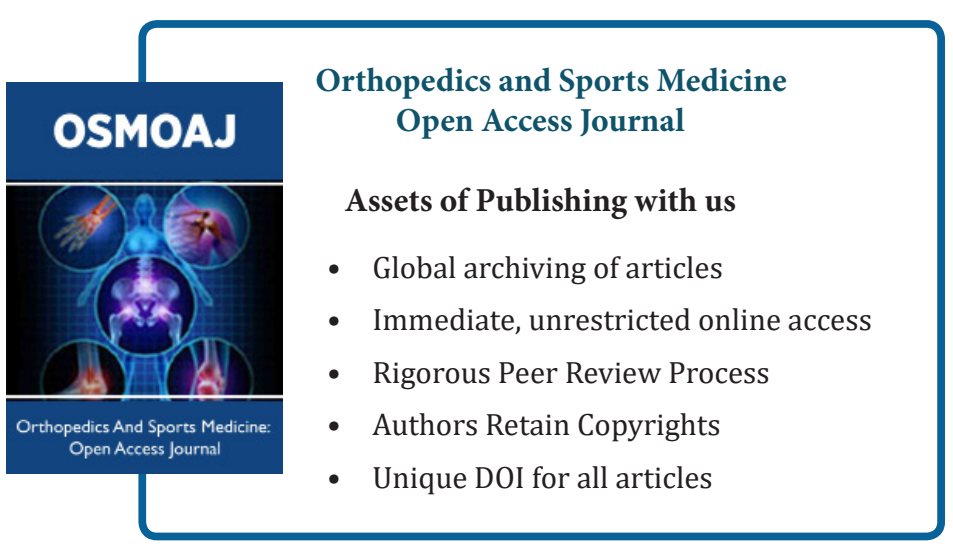

